\title{
The GAN Era has Arrived in SATCOM Power Amplifiers
}

\author{
Steve Turner* \\ Teledyne Paradise Datacom \\ LLC 328 Innovation Blvd., Sute 100, \\ State College, PA 16803 USA
}

Received 09.12.2014, received in revised form 26.01.2015, accepted 14.03.2015

In this paper features, characteristics and comparisons of gallium nitride high electron mobility transistors (GaNHEMTs) power amplifiers are considered.Maximumoperating temperature widespread now, gallium arsenide GaAs transistors is $175^{\circ} \mathrm{C}$. They are inferior to the transistors based on gallium nitride GaN, and keep steadily working frequency characteristics at operating temperatures up to $250^{\circ} \mathrm{C}$. This greatly reduces the problem of heat removal. These transistors operate at voltages up to $100 \mathrm{~V}$ against the maximum of $20 \mathrm{~V}$ for GaAs transistors at equivalent power output. Therefore, GaN transistors and power amplifiers, they are particularly relevant for applications in space exploration. In Paradise Datacom (USA) designed power amplifiers in different ranges of frequencies with a power output of up to 50 to 750 watts.

Keywords: gallium nitride high electron mobility transistors, amplifiers, power amplifiers.

\section{Эпоха GaN}

\section{в усилителях мощности САТКОМ}

\author{
C. Тёрнер \\ Teledyne Paradise Datacom \\ LLC 328, Инновачии бульвар, офис 100 \\ Государственный колледж, РА 16803, США
}

\begin{abstract}
B статье описаны функици, характеристики транзисторов GaN с высокой подвижностью электронов в усилителях мощности. Предельной рабочей температурой широко распространенных до настоящего времени арсенид-галлиевых GaAs-транзисторов является $175^{\circ} \mathrm{C}$. Они уступают транзисторам на основе нитрида галлия $\mathrm{GaN}$, устойчиво работающих и сохраняющих частотные характеристики при рабочих температурах до $2500{ }^{\circ} \mathrm{C}$. Это значительно уменьшает проблему отвода тепла. Эти транзисторы работают при напряжении питания до 100 В против максимально 20 В для GaAs-транзисторов при эквивалентной мощңности выходного сигнала. Поэтому GaN-транзисторы и усилители мощности на
\end{abstract}

(C) Siberian Federal University. All rights reserved

* Corresponding author E-mail address: vak-sfu@mail.ru 
них особенно актуальны для приложений в космической сфере. B Paradise Datacom (США) разработаны усилители мощности в различных диапазонах частот с мощностью выходного сигнала от 50 до $750 \mathrm{Bm}$.

Ключевые слова: нитрид галлия, транзисторы с высокой подвижностью электронов, усилители, усилители мощности.

\section{Introduction}

Gallium Nitride High Electron Mobility Transistors, GaNHEMTs, are fast becoming the amplifier designer's device of choice for applications ranging from pulsed radar to communication systems. This is primarily due to the high power density as compared to Gallium Arsenide, GaAs and high frequency capability as compared to LDMOS devices. For an equivalent semiconductor die physical size a GaN device can produce two to three times more RF output power. Along with the higher power density comes increased robust operation and reliability. The voltage breakdown of $\mathrm{GaN}$ devices is in excess of 100 volts compared to 7 to 20 volts for equivalent power GaAs devices. The key characteristics of $\mathrm{GaN}$ are:

- High Output Power,

- High Breakdown Voltage High Peak Current Capability,

- Good Efficiency,

- Low knee Voltage-High Breakdown Voltage combination,

- Low Semiconductor Losses,

- Ability to cutoff current at high voltage,

- High Reliability,

- High Temperature Operation,

- High Reliability,

- Low Thermal Resistance.

In the microwave frequency region, $\mathrm{GaN}$ device technology has exhibited higher gain than comparable GaAs devices. This leads to higher power added efficiency which is a very important parameter in amplifier design. Power added efficiency allows a given amplifier to be designed with fewer number of devices further leading to an amplifier that consumes a minimal amount of prime input power. This leads to the concept that GaN provides a "green" amplifier alternative. We can see that $\mathrm{GaN}$ has a wonderful set of mutually beneficial features for high power amplifier applications:

- Higher Gain,

- Greater Output Power Density,

- Ability to operate at higher device temperatures,

- Higher Power Added Efficiency,

- More immune to RF over-drive.

These characteristics make GaN the clear choice for high power amplifier design in frequency ranges from S-Band through Ka Band and beyond. The broad band capability of GaN has even been shown to be greatly beneficial in amplifier design in the VHF and UHF region [1].

Reliability is of paramount concern in the design of any solid state power amplifier. This is of special interest any time a new technology is introduced. A native GaN wafer is not possible due to the physical state differences between Gallium and Nitrogen. Thus the GaN lattice must be attached 


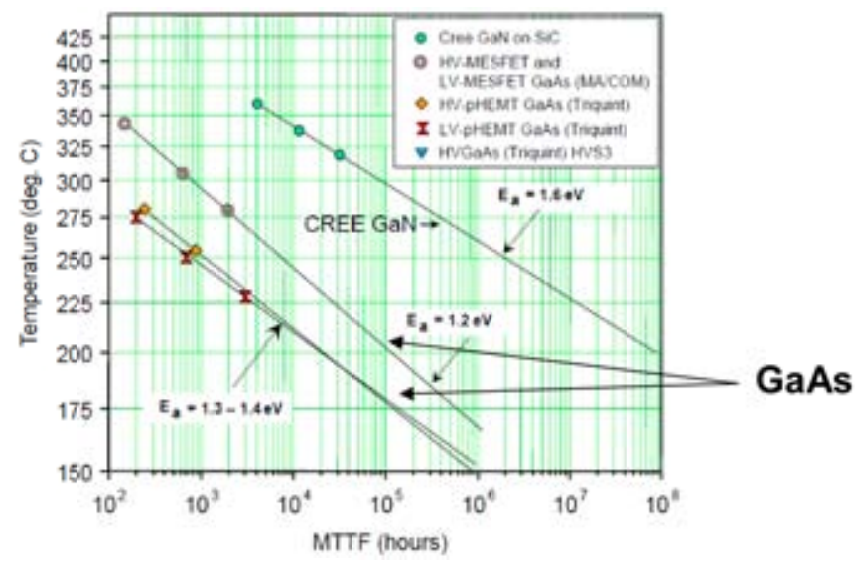

Fig. 1. Comparison of GaAs and GaNMTTFs. Courtesy of Cree Corporation

to a base substrate material using molecular beam epitaxy (MBE). Silicon carbide is the most popular substrate material due to its ability to solve the lattice mismatch as well as provide excellent thermal conductivity. While Silicon, $\mathrm{Si}$, is much lower cost, its poor thermal conductivity would result in dramatically less heat spreading and therefore higher channel temperatures. GaN semiconductors have been in development since the middle 1980s. Early experimentation with substrate materials such as silicon and sapphire contributed to the misconception that GaN devices had lower MTBF than GaAs devices. Since the near universal adoption of Silicon Carbide as a base substrate, GaN devices are now exhibiting MTBFs that are greater than their GaAs counterparts.

Contrast the GaN device MTTF to that of the GaAs device as shown in Fig. 1. The GaAs device achieves one million hour MTTF at a channel temperature of $175^{\circ} \mathrm{C}$. From the Arrhenius plot we can see that extremely high MTTFs are achievable from both GaN and GaAs devices assuming that good thermal design techniques are employed to keep the channel temperatures within the device manufacturer's recommended range. The GaN device can operate in excess of $250^{\circ} \mathrm{C}$ for the same one million hour MTTF. This shows the ability of $\mathrm{GaN}$ devices to operate at higher temperatures or achieve much higher reliability when operated at the same temperatures as GaAs devices. This means that amplifier engineers can potentially reduce the size of heat sinks and utilize minimal thermal engineering to realize reliable high power amplifiers. More importantly one can deduce that a GaN amplifier that is built upon the same thermal platform as its equivalent GaAs amplifier will be operating at significantly lower channel temperatures and will be able to achieve much higher MTTFs. GaN devices on $\mathrm{SiC}$ substrates can operate at higher channel temperatures than GaAs devices. Maximum GaN channel temperatures are in the $200^{\circ}$ to $250^{\circ} \mathrm{C}$ range. GaAs device equivalents are limited to channel temperatures in the $150^{\circ}$ to $175^{\circ} \mathrm{C}$ range.

\section{Satcom amplifiercomparizons}

\section{$100 \mathrm{~W}, \mathrm{X}$-Band SSPA}

Paradise Datacom's 100W GaAs X-Band SSPA in the Compact Outdoor enclosure consumes about $750 \mathrm{~W}$ of $\mathrm{AC}$ prime power and produces $50 \mathrm{~W}$ of linear output power. A GaN version of the module that produces the same $50 \mathrm{~W}$ of linear power consumes about $500 \mathrm{~W}$ of AC prime power. 


\section{$200 W, X$-Band SSPA}

Paradise Datacom's 200 W GaAs X-Band SSPA Compact Outdoor amplifier consumes about $1350 \mathrm{~W}$ of AC prime power while producing $80 \mathrm{~W}$ of linear output power. A GaN version of the module that produces the same $80 \mathrm{~W}$ of linear power consumes about $700 \mathrm{~W}$ of prime power. In this case we can see that the $\mathrm{AC}$ prime power consumed by the GaN amplifier is almost one half of its GaAs equivalent. Therefore as the output power of the amplifier increases, the difference in efficiency becomes more pronounced. Next let's consider the extreme case of the $400 \mathrm{~W}$ GaN amplifier.

\section{W GaAs vs. 400W GaN}

The highest power GaAsSSPA that Paradise Datacom offers in the Compact Outdoor enclosure is a $250 \mathrm{~W}$ unit. This amplifier produces $125 \mathrm{~W}$ of linear output power while consuming $1500 \mathrm{~W}$ of $\mathrm{AC}$ prime power. Due to the higher power density of the GaN devices, Paradise Datacom can package a 400W GaN amplifier in the same Compact Outdoor enclosure. This amplifier produces 200W of linear power and consumes about $1400 \mathrm{~W}$ of $\mathrm{AC}$ prime power. The GaN devices enable the Compact Outdoor SSPA to deliver nearly two times the linear output power while consuming about the same AC input power. Thus it is very easy to see how GaN amplifier technology can lead to dramatic savings in electricity costs to operate the amplifier.

As we move higher in frequency, the increased efficiency of $\mathrm{GaN}$ becomes even more important. This section describes the efficiency improvements that have been achieved in the Ku band by utilizing GaNSSPAs. One of the longest running and most popular Paradise Datacom SSPAs has been the 125W $\mathrm{Ku}$ Band GaAs amplifier. This amplifier that is packaged in the Compact Outdoor enclosure produces $50 \mathrm{~W}$ of linear output power. It consumes about $1000 \mathrm{~W}$ of AC prime power. This amplifier is being replaced by a $150 \mathrm{~W} \mathrm{Ku}$ Band GaNSSPA module that is physically the same size and, as such, is also packaged in the Compact Outdoor enclosure. The GaN module produces 80 to $90 \mathrm{~W}$ of linear output power. Furthermore this amplifier consumes about $700 \mathrm{~W}$ of AC prime power at the linear operating level. This is well over two times the linear power efficiency of the $125 \mathrm{~W}$ GaAsSSPA.

When considering the RF power combining efficiency at Ku band, we can quickly see that in order to achieve 80 to $90 \mathrm{~W}$ of linear output power capability, two $125 \mathrm{~W}$ GaAsSSPAs would be required

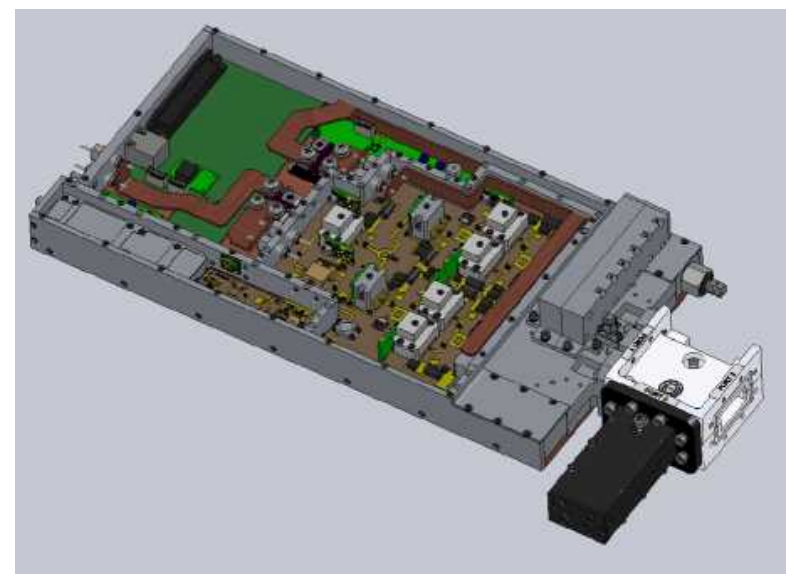

Fig. 2. 400W X-Band GaNSSPA Module 


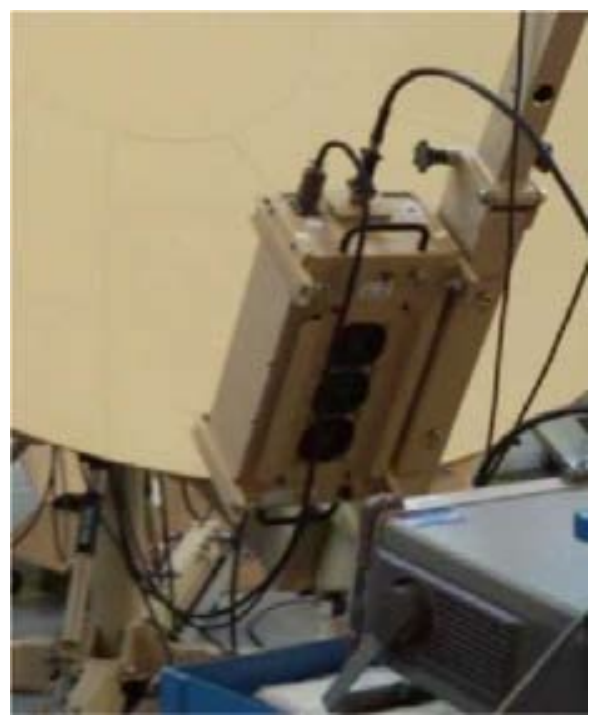

Fig. 3. 150W Ku Band GaNSSPA in the Compact Outdoor Enclosure

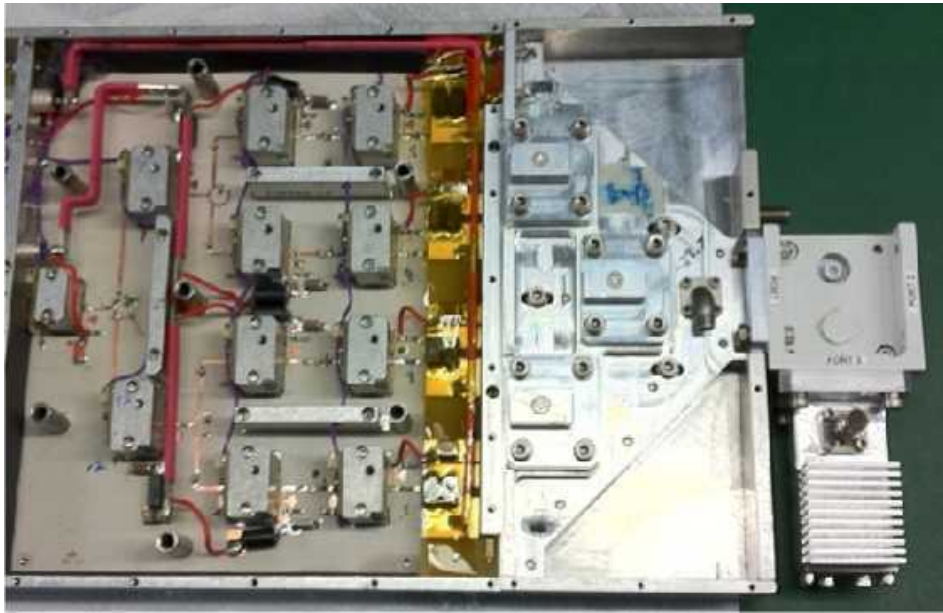

Fig. 4. 150W Ku Band GaNSSPA Module

in a phase combined system. Thus two SSPAs and all associated phase combined hardware would need to be purchased.

Even more impressive is the fact that the $150 \mathrm{~W}$ GaNSSPA has about the same sell price as a single $125 \mathrm{~W}$ GaAs unit. Therefore by utilizing the GaNSSPA at Ku Band, the customer can procure two times the output power capability at the price of a single GaAsSSPA. The end user of the equipment can reap the benefits of lower electricity costs to operate the amplifier. Two $125 \mathrm{~W}$ GaAsSSPAs would consume about $1800 \mathrm{~W}$ of AC prime power. By contrast the single $150 \mathrm{~W}$ GaNSSPA consumes $700 \mathrm{~W}$ of AC prime power at the linear operating point. It is clear that GaN devices will be rapidly replacing their GaAs counterparts in all SatCOM amplifier applications. 


\section{True power detection}

A new feature that exists on all Teledyne Paradise Datacom GaNSSPAs packaged in the Compact Outdoor enclosure is true RF output power detection. While technically not a byproduct of GaN technology per se, this feature is being introduced on all new GaN based SSPA modules.

Historically all HPA manufacturers have used diode based peak power detection circuitry in their products for the internal measurement of RF output power. This is the output power that is either reported on the local display of an indoor rack mount amplifier or by remote communications (RS485 and Ethernet). While this type of circuit can be calibrated to provide a fairly reading for a CW signal, this accuracy is dramatically degraded with the presence of multi-carrier traffic and digital modulation schemes with high peak to average power ratios. Typically the end user must attach a power meter to the RF sample port to obtain accurate RF output power measurements.

True power measurement gives a reading that is based on the rms voltage of the RF output waveform. This is often referred to as true rms output power. This feature essentially gives the user a 'built-in' power meter in the SSPA. Accurate RF output power is reported for all common modulation schemes encountered in Satcom systems including: QPSK, 8PSK, 16QAM, and OFDM. This power meter accuracy is maintained regardless of the number of carriers present in the passband. True power measurement is available on all GaNSSPAs above 200W from S-Band through Ku band. The Teledyne Paradise Datacom 150W Compact Outdoor SSPA is the only Ku Band SSPA in the SatCom industry to feature true output power measurement.

The RF power density and efficiency enhancements of $\mathrm{GaN}$ devices make possible a whole new generation of very high power SSPA systems. Power levels that were once only possible with Traveling Wave Tubes and Klystrons are easily and efficiently achieved with solid state GaN devices. A good example of is Teledyne Paradise Datacom's 5 kW S-Band Redundant System. This system shown in Fig. 5 is configured in 1:1 Redundancy for extremely high system MTTF. System MTBFs over 450,000 hours have been demonstrated with this system architecture.

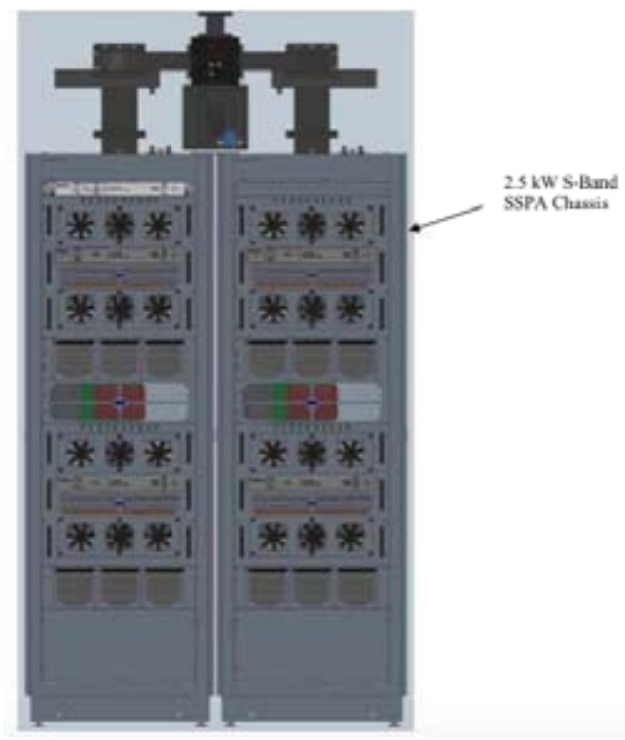

Fig. 5. 5kW GaN S-Band High Power Amplifier System in 1:1 Redundancy 
Each cabinet is comprised of (2) $2.5 \mathrm{~kW}$ S-Band SSPA chassis that are phase combined to achieve saturated power levels in excess of $5 \mathrm{~kW}$. Each 10RU SSPA chassis is comprised of (4) 800W SSPA modules. The entire solid state power amplifiercascade is realized using GaN device technology. Analog predistortionlinearization is used to enhance thelinearity of the amplifiersystem.

\section{Powermaxsspa systems}

Modular SSPA systems have been gaining popularity over the past 10 years. Teledyne Paradise Datacom's premiere modular HPA system is the PowerMAX architecture. The PowerMAX system can be populated with any number of SSPA modules ranging from (4) to (16). The system is based on $n+1$ modular redundancy. Thus a system with (8) modules is designed to be able to meet system specifications with only (7) modules operational. Every aspect of the system is pure parallel redundant including the each SSPA's embedded computer logic. All active components in the system are hotswap removable including the fans, power supply modules, and SSPA modules. There is never a need to power the system down for replacement of any module. Figure 5 shows a cabinet break-away view of Teledyne Paradise Datacom's 4 kW X- Band PowerMAX system. This system is comprised of (8) $650 \mathrm{~W}$ GaNSSPA modules. Using the PowerMAX architecture the HPA system is capable of higher reliability than any other form of amplifier system in these frequency bands. Using GaN technology enables the HPA system to achieve over $2 \mathrm{~kW}$ of linear output power in a system that consumes about $15 \mathrm{kVA}$ of AC prime power with built-in redundancy.

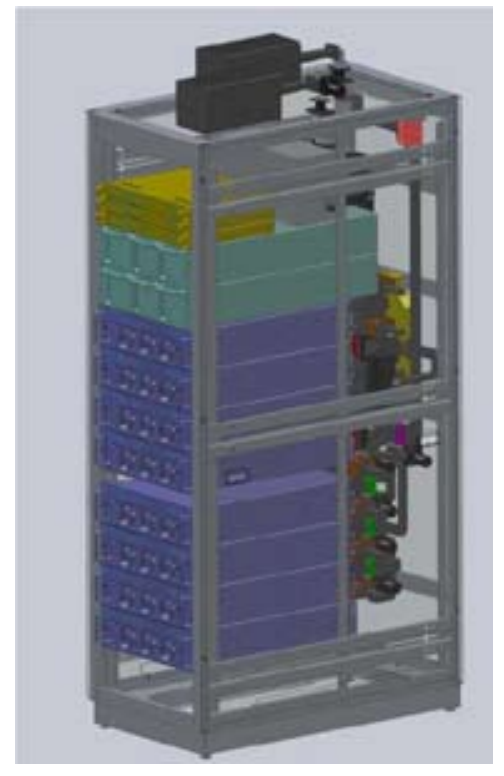

Fig. 6. 4 kW GaN X-Band PowerMAX n+1 Redundant High Power Amplifier System

\section{References}

[1] Turner S.D., Turner C.J. // Proceedings of the 2007 AMSAT-North America Space Symposium, Oct. 2007. P. 155-168. 